\title{
O USO PEDAGÓGICO DO SOFTWARE WINPLOT NA FORMAÇÃO DE PROFESSORES DE CÁLCULO
}

\section{THE PEDAGOGICAL USE OF WINPLOT SOFTWARE IN THE TRAINING OF CALCULATION TEACHERS}

Bergson Rodrigo Siqueira de Melo ${ }^{1}$

D ORCID iD: 0000-0003-0437-8062

Antonio Marcos da Costa Silvano ${ }^{2}$

ORCID iD: 0000-0001-7097-3674

Júlio Wilson Ribeiro ${ }^{3}$

ORCID iD: $\underline{0000-0002-9368-9585}$

Verônica Maria Lavor Silva de Melo ${ }^{4}$

(D) ORCID iD: 0000-0001-7707-8795

\begin{abstract}
RESUMO
Apresentamos, os resultados de uma prática pedagógica, relativa à formação de professores de Matemática, promovendo-se o uso das tecnologias digitais. A investigação foi concebida metodologicamente conforme os pressupostos da pesquisa qualitativa colaborativa e desenvolvida preliminarmente, a partir de uma oficina, composta por um grupo de 16 (dezesseis) professores, destacou o objetivo de mobilizar conhecimentos e saberes, para a apropriação e o uso pedagógico do software Winplot, na construção e análise de gráficos de funções aplicadas ao cálculo diferencial e integral. A prática agregou o aporte teórico da Teoria da Aprendizagem Significativa, segundo uma proposta construtivista do uso pedagógico das Tecnologias Digitais da Informação e Comunicação (TDIC). O estudo mostrou que foi predominante a satisfação por parte dos docentes em trabalharem colaborativamente, revelando indícios de que as contribuições do uso operacional e pedagógico do software Winplot auxiliam no desenvolvimento da integração e cooperação entre professores, bem como na apropriação dos pressupostos das tecnologias, o que possibilita perfazer uma reflexão a respeito do uso dos recursos digitais educativos, frente ao desenvolvimento do processo de ensino e aprendizagem de conceitos e representações de gráficos de funções.
\end{abstract}

Palavras-chave: Formação de professor. Winplot. Ensino e aprendizagem de matemática.

${ }^{1}$ Doutor em Educação pela Universidade Estadual do Ceará (UECE). Professor da Secretaria Municipal da Educação (SME), Fortaleza, Ceará, Brasil. Endereço para correspondência: Av. Des. Moreira, 2875 - Dionísio Torres, Fortaleza - CE, CEP: 60170-002. E-mail: bergson1melo@gmail.com.

${ }^{2}$ Doutor em Educação pela Universidade Estadual do Ceará (UECE). Professor do Instituto Federal de Educação do Ceará (IFCE), Cedro, Ceará, Brasil. Endereço para correspondência: Alameda José Quintino, s/n - Prado, Cedro - CE, CEP: 63400-000. E-mail: marcos.silvano@ifce.br.

${ }^{3}$ Doutor em Ciências pelo Instituto Tecnológico de Aeronáutica (ITA). Professor da Universidade Federal do Ceará (UFC), Fortaleza, Ceará, Brasil. Endereço para correspondência: Rua Waldery Uchôa, 01 - Benfica, Fortaleza - CE, CEP: 60020-110 E-mail: juliow@uol.com.br.

${ }^{4}$ Mestranda pelo Programa de Pós-Graduação em Ensino - PPGE da Universidade do Estado do Rio Grande do Norte (UERN). Professora da Secretaria Municipal da Educação (SME), Fortaleza, Ceará, Brasil. Endereço para correspondência: Av. Des. Moreira, 2875 - Dionísio Torres, Fortaleza - CE, CEP: 60170-002. E-mail: veronica.lavor@yahoo.com.br. 


\begin{abstract}
The results of a pedagogical practice for the formation of Mathematics teachers formation, promoting the use of digital technologies. The investigation was methodologically conceived based on the assumptions of qualitative collaborative research and developed preliminarily from a workshop with a group of 16 (sixteen) teachers whose aim was to mobilize knowledge for the appropriation and the pedagogical use of winplot software in the construction and analysis of graphs of functions applied to differential and integral calculus. The practice added the theoretical contribution of the Theory of Significant Learning, according to a constructivist proposal of the pedagogical use of Digital Technologies of Information and Communication (DTIC). The study showed that teachers' satisfaction in working collaboratively was predominant, revealing evidence that the contributions of the operational and pedagogical use of the winplot software help in the development of integration and cooperation between teachers, as well as in the appropriation of the assumptions of technologies, which makes it possible to reflect on the use of digital educational resources in order to promote the development of the process of teaching and learning concepts and representations of function graphs.
\end{abstract}

Keywords: Teacher training. Winplot. Mathematics teaching and learning.

\title{
1 INTRODUÇÃO
}

As Tecnologias Digitais da Informação e Comunicação (TDIC), cada vez mais, favorecem relevantes transformações e inúmeras possibilidades para sua utilização em diversos setores da sociedade, o que possibilita, em distintos cenários cotidianos, se perceber significativas mudanças na vida dos cidadãos, que estão se apropriando adequadamente desses recursos. No contexto educacional, mencionadas inovações tecnológicas continuamente promovem o surgimento de inovações e ressignificação quanto às concepções teóricas metodológicas dos processos de ensino e aprendizagem. Contudo, emergem de forma rizomática e gradativa, exigindo ainda se facilitar operacional e pedagogicamente o acesso e a utilização dos dispositivos digitais.

A operacionalização do uso pedagógico de softwares educativos no computador em sala de aula, se metodologicamente embasada, possibilita aos professores e alunos desenvolverem competências e habilidades, potencializando a apropriação de novos saberes e conhecimentos. Assim, se robustece ao professor a possibilidade de exercer o papel docente de mediador das práticas colaborativas e, aos estudantes, a condição de sujeitos protagonistas do desenvolvimento de suas aprendizagens. Nesse contexto, os conteúdos disciplinares de áreas de conhecimento como Matemática, Ciências, Estatística e outras podem ser explorados por meio de estratégias que possibilitem reflexões e questionamentos para construção de trabalhos interativos e colaborativos (ALMEIDA, VALENTE, 2011).

Nessa direção, os sujeitos envolvidos no processo de ensino e aprendizagem passam a conceber uma postura mais ativa, reflexiva e autônoma diante de diversas situações e 
contextos de aprendizagem que se caracterizem, fazendo o uso das potencialidades pedagógicas das TDIC. Inúmeras podem se caracterizar as vantagens em se utilizar operacional e pedagogicamente esses recursos, pois os computadores conectados à internet constituem ferramentas poderosas que podem auxiliar professores e alunos, interligando-os aos diversos meios de apropriação de informações, conhecimentos e saberes que a rede mundial de computadores possa oferecer.

O corrente artigo discute o processo de formação de professores de Matemática, realizada através de atividades desenvolvidas numa oficina para promover o uso pedagógico do software educativo Winplot, a partir da construção de representações gráficas de funções matemáticas, aplicadas aos conceitos de cálculo diferencial e integral.

O software educativo Winplot é gratuito e apresenta interface pedagógica considerada como simples, de fácil manipulação e interativa. Esse software faz parte da linha Peanut Softwares e foi desenvolvido pelo professor Richard Parris, da Philips Exeter Academy, nos Estados Unidos, em 1985 (SILVANO, 2011). O nome Winplot indica que o programa é usado para fazer gráficos de funções em Matemática, em uma plataforma Windows. Trata-se de um programa que disponibiliza uma interface pedagógica gráfica, de utilização geral, que permite a construção e animação de gráficos em duas dimensões (2D) e em três dimensões (3D), a partir da elaboração de arquivos de dados de entrada, expressos por determinados tipos de funções analíticas matemáticas, às quais devam ser atribuídos valores numéricos (SILVANO, 2011).

A mencionada formação incorporou em seu aporte teórico os pressupostos da Teoria da Aprendizagem Significativa Ausubeliana e a proposta construtivista do uso pedagógico das TDIC de Almeida e Valente (2011). O estudo foi realizado junto ao grupo de 16 (dezesseis) professores universitários que ministraram disciplinas de Cálculo Diferencial e Integral, além de outras disciplinas da área de Matemática, nos cursos de Engenharia Elétrica e Engenharia Civil de uma universidade particular de Fortaleza, e teve uma carga horária total de 20 (vinte) horas-aula. Os referidos professores possuem formação inicial específica na área de Matemática com especialização e mestrado e com experiência na docência de Matemática, especialmente na graduação, fato que nos motivou a investigar junto a eles o uso das tecnologias digitais da informação e da comunicação integradas às suas práticas pedagógicas. 


\section{INTEGRAÇÃo DAS TDIC E PRÁTICA PEDAGóGICA}

A integração das TDIC com a prática pedagógica colaborativa apresentada por diferentes autores, entre eles Almeida e Valente (2011); Ribeiro et al (2008a) e Okada (2008a), configura-se como a possibilidade de explorar suas potencialidades de animação e simulação por meio de softwares, como ferramenta auxiliar para facilitar o desenvolvimento da aprendizagem. As TDIC podem auxiliam o aprendiz no desenvolvimento de ciclo de ação, descrição, depuração e nova ação, por meio da espiral de aprendizagem (ALMEIDA, VALENTE, 2011; SILVANO, 2011), na qual o aprendiz poderá construir novos conhecimentos a partir da integração de seus conhecimentos prévios, estruturados significativa e cognitivamente (AUSUBEL, 2003).

O advento das tecnologias de informação e comunicação (TIC), resultante da junção entre informática e telecomunicações, gerou novos desafios e oportunidades para incorporação de tecnologias na escola em relação a diferentes formas de representação e comunicação de ideias. A característica de propiciar a interação e a construção colaborativa de conhecimento da tecnologia de informação e comunicação evidenciou o potencial de incitar o desenvolvimento das habilidades de escrever, ler, interpretar textos e hipertextos. (ALMEIDA, 2007, p.41).

De acordo com a autora, as tecnologias funcionam como uma nova linguagem que permite tecer um complexo e multidimensional elo entre pessoas e a aprendizagem. Nesse sentido, os softwares educacionais apresentam-se como ferramentas de imenso potencial, se utilizados de forma metodológica e pedagogicamente embasada, frente aos problemas inerentes aos processos de ensino e de aprendizagem. Neles podemos perceber a possibilidade de "mudar os limites entre o concreto e o formal" (PAPERT, 1988). O computador vem permitindo criar ou recriar um novo tipo de articulação dos conhecimentos e da comunicação com o uso dos espaços interativos digitais. É possível citar, por exemplo, os jogos interativos, as redes sociais, os objetos de aprendizagem digitais, que permitem a interação, facilitando as formas de comunicação e construção de novos conhecimentos com o uso do computador.

Segundo Almeida e Valente (2011) a apropriação pedagógica das TDIC pode desencadear uma mudança na concepção de abordagem pedagógica dos conteúdos disciplinares. Poderá ser um elemento que enriqueça os ambientes de aprendizagem, nos quais o aluno, interagindo com os entes desses ambientes, de maneira mais facilitadora, possa construir novos conhecimentos e se apropriar deles.

Para os autores, o aluno não deve ser mais treinado, adestrado ou ensinado por meio do instrucionismo, mas, sim, como sujeito protagonista quanto ao processo de construção do seu próprio conhecimento. Aqui podemos perceber uma mudança de abordagem pedagógica 
na perspectiva da construção de uma nova concepção do uso do computador na educação de forma construcionista.

Consoante Papert (1988), o construcionismo é uma abordagem construtivista do uso pedagógico do computador na educação, cujo foco é a aprendizagem do aluno: em vez de centralizar-se no professor e no ensino, o importante é a construção de conhecimentos significativos, e não a instrução. Em pleno século XXI, é estratégico utilizar o computador em sala de aula, pois ele pode ser pedagogicamente concebido, exercendo o papel de uma ferramenta didática, assim como os seus componentes, tais como os softwares educacionais.

Os computadores são utilizados para demonstrar conceitos que podem ser vistos inicialmente pelo aprendiz como abstratos, isso no caso da Matemática; por exemplo, os mesmos conceitos são preliminarmente apresentados aos alunos, e estes, por sua vez, poderão se apropriar de seus significados com a ajuda do computador. Entretanto, o ensino formativo da Matemática deve expressar particularidades cognitivas, sociais e afetivas, com o propósito de promover a independência e a autoconfiança do aluno (SILVA, D’AVILA, 2020).

É percebido que, através da concepção de situações de aprendizagem, que possam, separada ou combinadamente, envolver distintas atividades de modelagem, animação e facilitação de simulação de conceitos abstratos, mencionadas ações podem contribuir para que o computador seja mais facilmente usado, durante a realização de práticas pedagógicas, com a intenção de facilitar o desenvolvimento do ensino e da aprendizagem de Matemática (ALMEIDA, VALENTE, 2011; SILVANO, 2011).

Almeida e Valente (2011) contrapõem-se à proposição do uso dessa tecnologia como “máquina de ensinar", como postulava SKINNER (1904-1990), propondo que o computador seja um recurso didático capaz de auxiliar professores e alunos pedagogicamente, provocando possíveis mudanças na qualidade do ensino e da aprendizagem.

Assim, o ato de aprender Matemática através do uso do computador por meio de software educativo adequado impõe a tomada de posições tais como: inovar, ousar experimentar, interpretar, visualizar, induzir, conjeturar, abstrair, generalizar, deduzir, demonstrar e aplicar. Através do uso pedagógico da informática na aprendizagem de Matemática, o conhecimento é construído por meio de investigações, explorações e demonstração de situações-problema.

O domínio instrumental de uma tecnologia, seja ela qual for, é insuficiente para que o professor possa compreender seus modos de produção de forma a incorporá-la à prática. É preciso criar situações de formação contextualizada, nas quais os educadores possam utilizar a tecnologia em atividades que lhes permitam interagir para resolver problemas significativos para sua vida e trabalho. (ALMEIDA, 2007, 
p.160).

A pesquisadora nos alerta que a tecnologia deve ser usada de forma racional e de modo que possa ser uma ferramenta de aprendizagem significativa; dessa forma, a internalização e a apropriação dos conhecimentos matemáticos por parte dos alunos, de todos os níveis de escolaridade, permanecem como desafio para o professor.

Segundo Ausubel (2003), a aprendizagem significativa é concebida por meio de um processo de construção de conhecimentos, em que um novo conhecimento se relaciona e ancora-se aos conhecimentos prévios existentes na estrutura cognitiva do aprendiz, de forma substantiva e não arbitrária. Para ele, o fator mais importante para a ocorrência da aprendizagem significativa é aquilo que o aluno já possui internalizado em sua estrutura cognitiva, possibilitando assim expandir seu universo de conhecimentos.

Nesse cenário, a aprendizagem significativa ocorre quando uma nova informação se relaciona com um aspecto relevante da estrutura de conhecimento do indivíduo. Ou seja, neste processo, a nova informação interage com uma estrutura de conhecimento específica, a qual Ausubel define como conceito subsunçor ou, simplesmente, subsunçor (subsumer), existentes na estrutura cognitiva do indivíduo.

Assim, o termo subsunçor pode ser definido como os conhecimentos existentes na estrutura cognitiva do educando. Portanto, os subsunçores podem propiciar sentido e significado aos novos conhecimentos que serão assimilados significativamente.

$\mathrm{Na}$ ausência de subsunçores, não é possível haver aprendizagem significativa e, nesse caso, ocorre a aprendizagem mecânica, na qual o educando memoriza as novas informações, que não guardam nenhuma relação com os conhecimentos previamente organizados em sua estrutura cognitiva.

Ausubel define a aprendizagem mecânica como sendo aprendizagem de novos conhecimentos de forma literal, arbitrária e não substantiva, na qual as informações são armazenadas de modo que não ressignificam os conhecimentos subsunçores do aprendiz. $\mathrm{O}$ conhecimento assim adquirido fica arbitrariamente distribuído na estrutura cognitiva sem relacionar-se a conceitos subsunçores específicos (MOREIRA, 2011).

A aprendizagem mecânica destaca sua importância nesse contexto, pois, à medida que o educando desenvolve os conceitos subsunçores relevantes, a sua estrutura cognitiva poderá converter a aprendizagem mecânica em aprendizagem significativa. Ausubel não estabelece a distinção entre aprendizagem significativa e mecânica como sendo uma dicotomia, e sim como um continuum. 
A aquisição de conhecimentos vem se tornando, a cada dia, mais compartilhada por parte dos alunos, isso por vários motivos, sejam de ordem cognitiva, sejam de ordem organizacional, sejam até mesmo de interesse particular (OKADA, 2008a). A implantação de inovações com novas metodologias mediadas pelas TDIC no contexto do ensino, que possam impulsionar a aprendizagem, poderá contribuir para tornar a Matemática uma disciplina mais atrativa em todos os níveis de ensino. Essas inovações, aliadas a uma abordagem mediadora, vêm sendo praticadas no ensino da disciplina em sala de aula, provocando mudanças no processo ensino e aprendizagem.

\section{SOFTWARE EDUCATIVO WINPLOT: USO OPERACIONAL E PEDAGÓGICO}

O software educativo Winplot é um programa de domínio público desenvolvido pelo professor Richard Parris, da Philips Exeter Academy, em 1985, com a finalidade de plotar gráficos de funções no plano e no espaço com diversas formas de entrada de funções, como funções explícitas, implícitas, polar, cilíndricas e esféricas. Foi traduzido recentemente para a Língua Portuguesa pelo professor Adelmo de Jesus, da Universidade Federal da Bahia, e está disponível para download no link http://math.exeter.edu/rparris (MAIA, 2007; SILVANO, 2011).

Esse software expressa a vantagem de ser considerado simples e utilizar pouca memória, porém é uma ferramenta pedagógica que dispõe de vários recursos que o podem tornar atraente e útil aos diversos níveis e modalidade de ensino, propiciando a professores e alunos a utilização em situações que envolvam os conceitos algébricos e geométricos de representações de gráficos de funções (MAIA, 2007; SILVANO, 2011).

O uso operacional desse software possibilita a construção, a análise e a interpretação de gráficos de funções destacando elementos como crescimento, decrescimento, pontos de máximos e de mínimos, zeros da função, ponto de inflexão, assíntotas, entre outros. Explorando pedagogicamente os recursos disponíveis, é possível projetar objetos na tela do computador sobre os gráficos das funções, bem como calcular áreas de superfícies compreendidas entre gráficos de funções e eixos coordenados ou entre gráficos de funções considerados conteúdos disciplinares relevantes das disciplinas de Cálculo Diferencial e Integral (CDI).

O uso operacional do software Winplot é concebido com a manipulação de funções explícitas, por meio das janelas de entrada de informações que são executadas, obedecendo aos comandos conforme os procedimentos adotados. Para construir o gráfico de uma função 
no plano usando o Winplot, o educando precisa seguir os passos: clicar no ícone "janela" e escolher o comando "2-dim”, o qual apresenta um quadro do plano cartesiano, onde deve selecionar o ícone "equação" e selecionar a forma "explícita”. Após esses procedimentos, aparecerá uma janela com um campo para que possa digitar a função desejada e definir o intervalo numérico de construção do gráfico da referida função.

Assim, na construção do gráfico da função $f(x)=x^{2}+2 x$ no intervalo fechado $[-1,2]$, seguindo esses passos anteriormente descritos, o educando deve inserir a expressão $x^{\wedge} 2+2 x$ no campo da função explícita, daí termos a representação gráfica conforme a figura 1.

Também é possível calcular a área da região limitada pela função, em relação ao eixo horizontal, utilizando o recurso "integração" disponível no software definindo os limites de integração e a quantidade de subintervalos para determinar o valor, aproximadamente, da integral definida da função.

Figura 1 - Representação gráfica da função $f(x)=x^{2}+2 x$ com o uso do software Winplot.

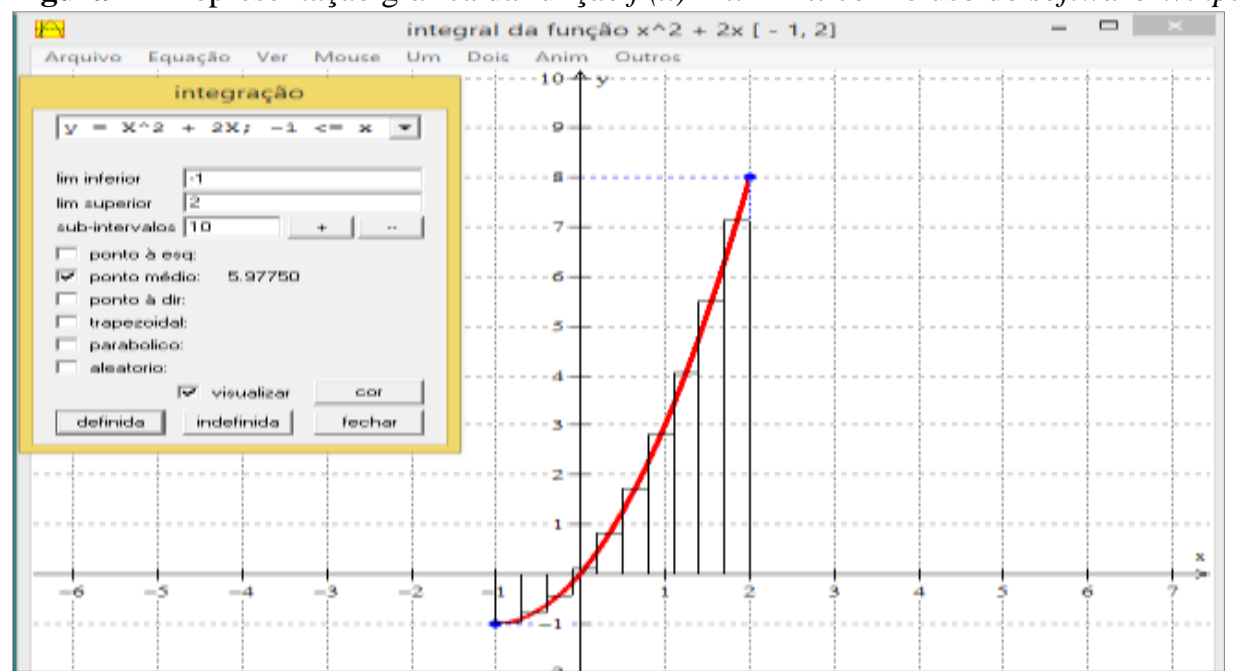

Fonte: Elaborado pelos autores (2020).

O uso operacional e pedagogicamente embasado do software educativo Winplot possibilita a superação das limitações do ensino tradicional instrucionista, com o uso de lápis e papel, ampliando as capacidades de análises na construção e animação interativa de vários gráficos de funções num mesmo plano, permitindo o desenvolvimento dos diversos estágios da construção colaborativa e significativa de novos conhecimentos. Na figura 2, apresentamos o mapa conceitual que sintetiza o uso operacional e pedagógico do software Winplot. 
Figura 2 - Mapa conceitual do uso operacional do software educativo Winplot para auxiliar a construção interativa de novos conhecimentos.

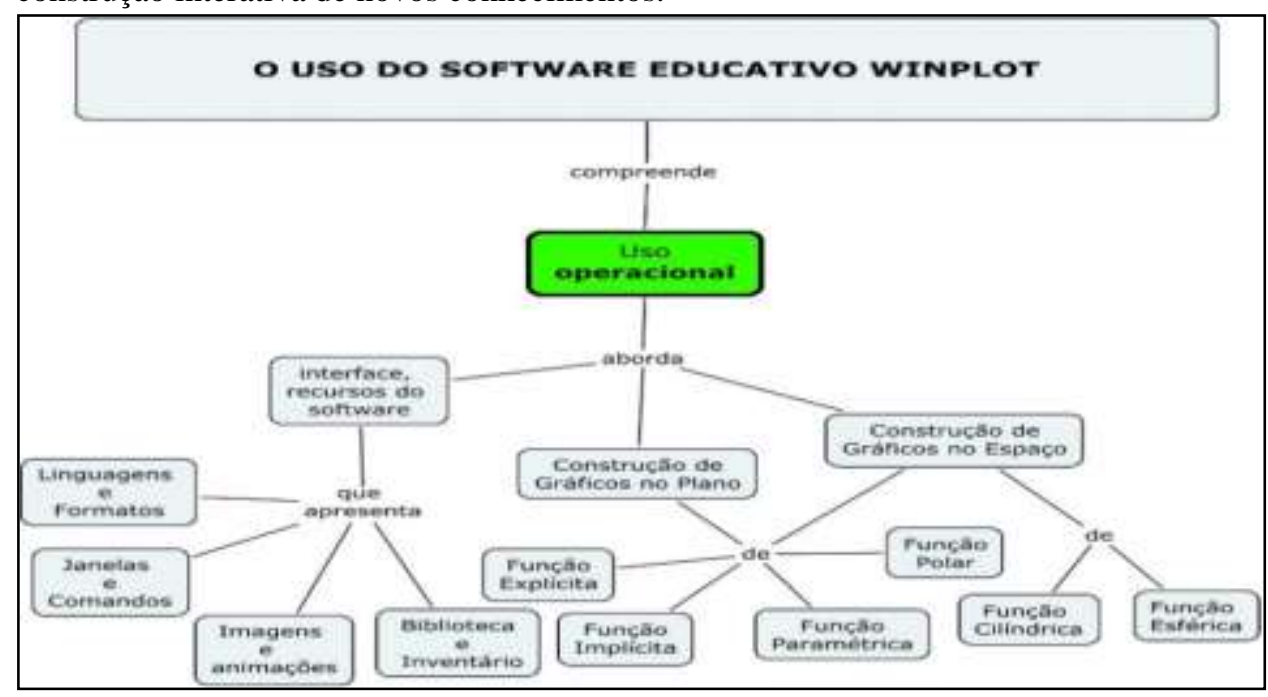

Fonte: Elaborado pelos autores (2020).

Observamos, no mapa conceitual da Figura 2, que o uso operacional do software educativo Winplot está relacionado com os aspectos que se limitam aos procedimentos que podem ser acessados, por meio dos recursos disponíveis no software, para a construção dos gráficos de funções. Esses recursos disponíveis na interface do Winplot possibilitam a escolha do tipo de linguagem formada, das janelas, dos comandos, das imagens, das animações, da biblioteca e do inventário, bem como do tipo de função que se deseja construir o gráfico, no plano (2D) ou no espaço (3D).

O uso pedagógico de software educativo Winplot possibilita aos professores e alunos ampliarem as possibilidades em relação ao processo de ensino e de aprendizagem de Matemática, superando eventuais obstáculos cognitivos inerentes ao desenvolvimento de novas competências e habilidades.

Por meio do uso pedagógico do software educativo Winplot, como recurso pedagógico na Educação Matemática, é possível desenvolver conhecimentos, competências e habilidades dos educandos com atividades interativas e colaborativas, e o professor passa a desenvolver uma transposição didática mais recursiva na mediação e na avaliação do aprendizado.

Silvano (2011) comenta, a partir de análises das Orientações Curriculares Nacionais do Ensino Médio (OCNEM), relativo ao uso pedagógico de softwares no ensino e na aprendizagem de Matemática, que:

[...] Há programas de computador (softwares) nos quais os alunos podem construir diferentes conceitos matemáticos, referidos a seguir como programas de expressão. Programas de expressão representam recursos que provocam, de forma muito natural, o processo que caracteriza o pensar matematicamente, ou seja, os alunos 
fazem experimentos, testam hipóteses, esboçam conjecturas, criam estratégias para resolver problemas (OCNEM apud SILVANO, 2011, p. 21).

Nesse sentido, alunos e professores podem articular e mobilizar seus conhecimentos prévios, explorando as potencialidades e os recursos do software para construir novos conhecimentos, de forma significativa, por meio da descrição, reflexão e depuração das informações obtidas com manipulação e análises das interpretações construídas com o auxílio do programa, sobre a construção pedagógica (VALENTE, 2006; ALMEIDA, VALENTE 2011), e da aprendizagem significativa (AUSUBEL, 2003).

De acordo com Almeida e Valente (2011), o educando, utilizando o computador de forma construtivista, pode construir e ressignificar seu conhecimento, de modo a criar, pensar, manipular informações e promover sua autonomia inerente ao processo educativo, refletindo na sua aprendizagem.

Nesse sentido, o uso pedagógico do software Winplot permite aos professores e alunos investigarem, de forma didática, os aspectos gráficos e algébricos de funções matemáticas, bem como realizar animações de gráficos na tela do computador e simular situações-problema envolvendo o cálculo de limites, derivadas e integrais dessas funções.

$\mathrm{Na}$ figura 3, apresentamos o mapa conceitual que sintetiza o uso pedagógico do software Winplot.

Figura 3 - Mapa conceitual do uso do software Winplot

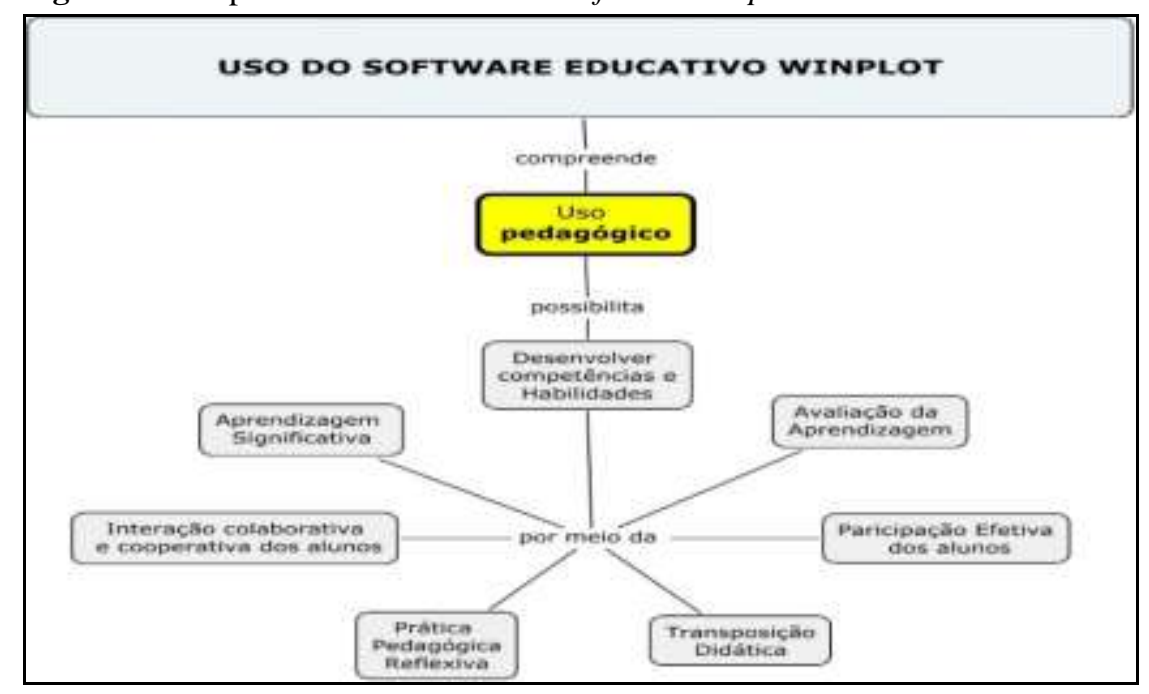

Fonte: Elaborado pelos autores (2020).

Verificamos, no mapa conceitual da Figura 3, as possibilidades e concepções do uso pedagógico do software educativo Winplot a partir da visão construtivista da utilização dessa ferramenta, explorando suas potencialidades no contexto educacional. $\mathrm{O}$ uso fundamentado do software permite propiciar a articulação de novos conhecimentos, por meio da 
aprendizagem significativa e colaborativa, desenvolvendo competências e habilidades no processo de ensino e aprendizagem de Matemática.

\section{PERFIL DOS PROFESSORES PARTICIPANTES, METODOLOGIA, DISCUSSÕES E RESULTADOS}

Nesta investigação, foi necessária a caracterização do perfil dos professores participantes da pesquisa para que pudéssemos construir as análises a respeito das contribuições da investigação na formação dos professores, bem como na definição dos passos adotados metodologicamente na pesquisa.

Os sujeitos da pesquisa foram 16 (dezesseis) professores de uma Universidade particular da cidade de Fortaleza. Eles apresentam, em média, entre 10 e 20 anos de experiência profissional no magistério e possuem vínculo de trabalho de 3 a 15 anos nessa Universidade, lecionando a disciplina de Cálculo Diferencial e Integral, além de outras disciplinas da área de Matemática.

Os docentes sujeitos da pesquisa possuem graduação em Matemática e também pósgraduação Lato Sensu e Stricto Sensu; em algumas atividades do dia a dia, eles fazem uso das TDIC, mais especificamente utilizam os computadores e softwares educativos em sua prática docente, e manifestaram interesse e receptividade em colaborar com a investigação.

O procedimento adotado na metodologia da pesquisa foi gerado a partir da realização de uma oficina com um grupo de professores. A pesquisa foi classificada como qualitativa e colaborativa.

A abordagem da pesquisa colaborativa caracteriza-se pelo envolvimento dos participantes na construção de novos conhecimentos, buscando maior aproximação e mediação pedagógica para o desenvolvimento profissional.

De acordo com Ribeiro et al (2008a), as pesquisas colaborativas propiciam uma investigação pautada no uso da reflexão e na prática colaborativa, por meio de adoção de procedimentos que permitam estabelecer uma melhor integração e compreensão das ações e do planejamento para o desenvolvimento de estratégias de resolver situações-problema.

Durante o transcurso da oficina, foi aplicado um instrumento para coleta de dados junto aos participantes, por meio de um questionário semiestruturado, abordando o uso operacional e pedagógico do software Winplot nas aulas de cálculo. Fizermos também registros das falas dos professores para serem analisados posteriormente. Nesse processo, os dados foram coletados durante a realização da oficina no percurso de três etapas: 
- Primeira etapa: Atividade com duração de 8 (oito) horas que compreendeu o levantamento de conhecimentos prévios dos professores, relativos ao uso das TDIC, e socialização da utilização pedagógica do uso do software Winplot abordando os conteúdos dos gráficos de funções aplicadas no estudo do cálculo. A pesquisa prosseguiu motivando os participantes a agirem de acordo com a abordagem colaborativa.

- Segunda etapa: Atividade com duração de 8 (oito) horas que proporcionou a construção coletiva e colaborativa de representações gráficas de funções matemáticas associadas ao estudo do cálculo, através do uso operacional do software Winplot, e reflexões sobre perspectivas pedagógicas com essa ferramenta.

- Terceira etapa: Aplicação do questionário composto por 10 (dez) questões objetivas e subjetivas, que versavam sobre os aspectos operacionais e pedagógicos do uso do software educativo Winplot. Durante essa etapa, que durou 4 (quatro) horas, foram discutidos e avaliados os pontos que abordavam as questões sobre a facilidade do uso do software, sua utilização e sua relação com o ensino e a aprendizagem do cálculo.

$\mathrm{Na}$ fase de coleta de dados, os participantes tiveram autonomia para explicitar suas posições e sugestões, pois os professores que ministraram a oficina desempenharam o papel de mediadores, buscando interferir o mínimo possível na elaboração das ponderações do grupo.

Durante a oficina, foram realizadas intervenções pedagógicas, discussões relativas aos conteúdos de cálculo com ênfase na análise e interpretação de representações de gráficos de funções, assim como esclarecimentos sobre eventuais dificuldades ou dúvidas apresentadas em relação ao uso do Winplot e dos conceitos da Matemática explorada. Com os resultados da análise dos dados, foram feitas as considerações e conclusões da pesquisa e discutidos os possíveis caminhos que nos apontam para o ensino e a aprendizagem mediada por tecnologias digitais, mais especificamente pelo uso do software Winplot.

Para proceder a análise e discussão dos resultados, utilizamos nomes fictícios para identificar os sujeitos da pesquisa. Assim, os participantes foram identificados por letras do alfabeto conforme a inicial de seu primeiro nome. A partir daí, selecionamos os comentários dos questionários de 6 (seis) professores que participaram efetivamente da oficina, pois consideramos relevantes suas respostas para formalizar a nossa discussão.

Analisando as contribuições dos sujeitos da pesquisa, após aplicação do questionário, que buscava compreender as concepções construídas pelos professores a respeito do uso do software Winplot em contextos de ensino e aprendizagem na disciplina de Cálculo, foi possível construir novas reflexões, discussões e maturações subjacentes ao processo de 
aquisição de novos conhecimentos com o uso operacional e pedagógico do software educativo Winplot.

Nesse sentido, explicitamos as contribuições do grupo e suas ponderações concernentes ao uso desses recursos integradas à sua prática pedagógica à luz do referencial teórico.

Verificamos, preliminarmente, por meio dos registros das observações, que os sujeitos da pesquisa têm um estruturado conhecimento prévio relevante relativo ao uso operacional das TDIC a partir de suas experiências e necessidades profissionais (uso de recursos interativos, computador, internet, uso de planilhas eletrônicas, entre outros) e formativas (estudos, pesquisas na web, sites de busca, entre outros) que eles consolidaram durante sua vida profissional.

Esse fato nos remete à afirmação de Ausubel (2003), a qual assinala que o fator isolado que mais influencia na aprendizagem do educando é aquilo que ele já sabe, ou seja, seus conhecimentos prévios relevantes com potencialidade de ancorar novos conhecimentos. Nesse sentido, os conhecimentos prévios dos participantes foram considerados importantes para a condução e o desenvolvimento da pesquisa colaborativa, uma vez que serviram de base para apoiar a construção de novos conhecimentos relativos ao uso e à apropriação operacional e pedagógica do software Winplot.

Outro aspecto observado foi os participantes manifestarem interesses e motivação na construção de saberes para a integração do uso das tecnologias digitais (software Winplot) ao processo de ensino e aprendizagem de Matemática.

Esse aspecto teve destaque no percurso da pesquisa, pois a predisposição do educando para aprender, de acordo com a teoria ausubeliana, é um dos fatores essenciais para a ocorrência da aprendizagem significativa integrada ao material potencialmente adequado à sua estrutura cognitiva (AUSUBEL, 2003).

Almeida e Valente (2011) afirmam que professores gradativamente estão buscando se apropriar das TDIC para a facilitação da aprendizagem dos alunos e para auxiliá-los na mediação pedagógica dos conteúdos disciplinares em sala de aula, e esse processo começa pela identificação e interação do professor com o assunto.

Os relatos dos professores participantes possibilitaram perceber uma afinidade com a proposta de trabalho da pesquisa na perspectiva da aprendizagem significativa e do uso operacional e pedagógico do software educativo Winplot, uma vez que apontaram perspectivas para superação das limitações (simulação e animação gráfica) no processo de ensino e aprendizagem do cálculo. 
Analisando as considerações dos professores em relação às perguntas do questionário que tratava sobre as possibilidades e as limitações do uso do software Winplot como ferramenta pedagógica para auxiliar professores e alunos nas aulas de Cálculo, destacamos estas:

Professor A: Beneficia a aprendizagem do aluno por ser um software simples e proporciona uma visão positiva do aluno a respeito de gráficos de funções sem a necessidade de se perder tempo desenhando o gráfico no caderno. Torna a aula mais interativa e interessante ao aluno, o que reflete em sua absorção do conhecimento.

Professor B: Ele é muito eficaz para validar os conteúdos teóricos e, até mesmo, mostrar mecanismos de construção de determinados algoritmos.

Ao analisarmos as contribuições dos professores A" e "B", verificamos que suas argumentações convergem no sentido de o software Winplot auxiliar alunos e professores na construção de gráficos de funções no plano, minimizando o esforço e o tempo, caso fossem construídos com lápis e papel, permitindo uma visualização instantânea (SILVANO 2011), além de possibilitar maior interatividade entre alunos e professores na construção de novos conhecimentos matemáticos (VALENTE, 2006; ALMEIDA, VALENTE 2011).

A partir das reflexões dos professores, foi possível verificar indícios de que o uso das tecnologias digitais por meio do software educativo Winplot integradas à prática pedagógica propicia ao professor construir novas abordagens pedagógicas, ressignificando sua prática (RIBEIRO et al 2008a), facilitando a mediação dos conteúdos de CDI e promovendo aprendizagem significativa de conceitos matemáticos, como testar e validar hipóteses, fazer experimentos e construir estratégias para resolver problemas (ALMEIDA, VALENTE, 2011; SILVANO, 2011).

Outras questões que mereceram destaque em nossa análise foram as que tratavam se a utilização o software educativo Winplot para a construção de representações gráficas de funções envolvendo CDI possibilitou melhor compreensão dos conceitos de função. Analisamos as contribuições dos professores " $D$ " e "F", que descreveram:

Professor D: Sim, facilita a visualização de gráficos da função através de simulação, evitando trabalhar exclusivamente com lápis e papel, além de possibiliar animação e construção de vários gráficos no mesmo plano.

Professor F:Gostei da utilização do software, vai me ajudar nas minhas aulas de Cálculo II. 
Os comentários dos professores " $\mathrm{D}$ " e " $\mathrm{F}$ " foram bem sucintos, porém, analisando-os qualitativamente, podemos perceber visões práticas do uso desse software educativo, pois, explorando os aspectos de visualização e simulação das representações gráficas de funções matemáticas, é possível conceituar melhor essas funções, identificando elementos essenciais e necessários para a compreensão do conteúdo, como domínio, imagem, crescimento, decrescimento, máximos, mínimos, raízes, entre outros (SILVANO, 2011).

Nesse sentido, verificamos que a utilização do software educativo Winplot possibilita melhor compreensão dos conceitos de função, permitindo ao educando articular e mobilizar seus conhecimentos prévios para a construção de novos conhecimentos significativos relativos ao conteúdo das funções matemáticas quando usado adequadamente à proposta pedagógica.

Ainda analisando as considerações dos professores relativas às questões que tratavam sobre as dificuldades dos alunos em compreenderem os conceitos de limites de uma função contínua, dois participantes relataram que:

Professor C: As dificuldades dos alunos normalmente estão relacionadas os conceitos básicos do Ensino Médio, pois eles até que entendem as definições dadas, mas não sabem fazer os procedimentos, as análises gráficas e as devidas operações.

Professor H: Uma dificuldade inicial é o reduzido embasamento conceitual para a construção de gráficos por parte dos alunos.

Verificamos, a partir dos comentários evidenciados pelos professores " $\mathrm{C}$ " e " $\mathrm{H}$ ", que um fator diretamente atrelado às dificuldades dos alunos na construção dos conceitos de limites das funções é a ausência de conhecimentos prévios para integrá-los aos novos conhecimentos (AUSUBEL 2003; MOREIRA, MASINI 2006). Esse fato dificulta o processo de desenvolvimento de competências e habilidades para a comprensão dos conceitos de CDI, uma vez que esses conceitos serão assimilados mecanicamente.

Constatamos, através de nossas análises, que os professoes participantes efetivaram de forma satisfatória o uso operacional e pedagógico do software Winplot e apresentaram afinidade e predisposição em utilizarem as TDIC no contexto de ensino e aprendizagem de Matemática, reconhecendo a importância desses recursos para a facilitação da aprendizagem dos educandos, bem como as pontencialidades das tecnologias digitais na superação dos desafios e obstáculos em sala de aula.

Os professores, ao sinalizarem que o uso do software educativo Winplot pode facilitar a aprendizagem e auxiliar na mediação pedagógica da disciplina de Cálculo Diferencial e 
Integral, nos levaram a analisar que a utilização de ferramentas computacionais integradas à Teoria da Aprendizagem Significativa contribui de forma efetiva para a construção de novas abordagens de ensino e aprendizagem.

Além disso, percebemos, durante a investigação, que foi predominante o envolvimento por parte dos docentes em trabalharem colaborativamente, e isso permitiu reforçar que as contribuições do uso operacional e pedagógico do software ajudam na integração e cooperação de professores na apropriação dos pressupostos das TDIC na perspectiva da aprendizagem significativa.

\section{CONSIDERAÇÕES FINAIS}

A pesquisa permitiu verificar, a partir da realização da investigação, possibilidades efetivas para o uso operacional e pedagógico do software educativo Winplot, numa perspectiva construtivista e colaborativa, no processo de mediação pedagógica de construção, análise e interpretação de representações gráficas de funções matemáticas na disciplina de Cálculo para promover o desenvolvimento de competências e habilidades, na procura de ressignificar novos conhecimentos.

O estudo nos permitiu também avaliar o campo de conhecimentos prévios dos professores, relativos ao uso operacional e pedagógico das TDIC no processo de ensino e aprendizagem de Cálculo, pois foram aplicados para esse fim a observação dos professores pesquisadores e o questionário interrogativo com perguntas objetivas e subjetivas dando ênfase ao uso desses recursos como estratégia pedagógica. Percebemos indícios de que os professores estão se apropriando gradativamente das TDIC, adequando-as ao seu interesse, e motivados em utilizar as tecnologias para auxiliar o processo de ensino e de aprendizagem.

Nesse sentido, a pesquisa nos possibilitou analisar, por meio de observação e dos procedimentos adotados na fase de interação com os professores, os campos de conhecimento construídos de forma colaborativa quando se concebeu e integrou o uso pedagógico das TDIC à prática pedagógica dos professores na disciplina de Cálculo, com o auxílio do software educativo Winplot para a construção das representações gráficas das funções matemáticas.

O resultado das análises das contribuições dos participantes da pesquisa nos possibilitou uma reflexão acerca do uso dos recursos das tecnologias digitais com o auxílio do software educativo no processo de ensino e aprendizagem, facilitando as inter-relações entre conceitos e representações de funções no plano por meio de ciclos de ação, descrição, reflexão e maturação das questões relativas ao cálculo (limites, derivadas e integrais). 
Pudemos perceber que a oficina pedagógica propiciou aos professores motivação e estímulo para utilizarem as TDIC em sala de aula, com o uso do Winplot para facilitar e auxiliar a mediação pedagógica e construir uma aprendizagem significativa .Uma das finalidades desse trabalho no campo da Educação Matemática foi tentar promover mudanças na prática pedagógica dos professores, contribuindo com novas estratégias pedagógicas, para subsidiar alunos e professores na disciplina de Cálculo, de forma significativa e colaborativa, pois, em alguns casos, essa disciplina é abordada de forma instrucionista e assimilada mecanicamente pelos alunos e, quando mediada pelas TDIC, favorece a aquisição de um significado mais realístico.

\section{REFERÊNCIAS}

AUSUBEL, D. Aquisição e Retenção de Conhecimentos: Uma Perspectiva Cognitiva. Lisboa: Plátano Edições Técnicas, 2003.

ALMEIDA, M. E. B. Integração de tecnologias à educação: novas formas de expressão do pensamento, produção escrita e leitura. In: VALENTE, José A. ALMEIDA, Maria E. B. (Org). Formação de educadores a distância e integração de mídias. São Paulo: Avercamp, 2007.

ALMEIDA, M. E. B. de VALENTE, J. A. Tecnologias e currículo: trajetórias convergentes ou divergentes? São Paulo: Paulus, 2011.

MAIA, D. Função quadrática: Um estudo didático de uma abordagem computacional. Dissertação de Mestrado. Programa de Pós-Graduação em Educação Matemática. PUC-SP, 2007. Disponível em: https://tede2.pucsp.br/handle/handle/11133. Acesso em 12 dez. 2019.

MOREIRA, M.A. Aprendizagem significativa: a teoria e texto complementares. São Paulo: Editora Livraria da Física, 2011.

MOREIRA, M. A; MASINI, E. F. S. Aprendizagem significativa: a teoria de aprendizagem de David Ausubel. São Paulo: Centauro Editora. $2^{a}$ edição, 2006.

PAPERT, S. Logo: computadores e educação. São Paulo: Editora Brasiliense, 1988.

OKADA, A. L. P. O que é cartografia cognitiva e por que mapear redes de conhecimento? In: OKADA. A. (Org.). Cartografia Cognitiva - Mapas do conhecimento para pesquisa, aprendizagem e formação docente. Cuiabá, MT: KCM, p. 39-65, 2008a.

RIBEIRO, J. W; VALENTE, J. A; FREITAS, D. B; MARTINS, D. G; SANTOS, M. J. C. Integração de atividades de educação em ciências utilizando TIC: uma experiência na formação continuada de educadores do ensino médio. SEMINÁRIO WEB CURRÍCULO I, 2008a, São Paulo. Anais eletrônicos. São Paulo: PUC-SP, 2008a. Disponível em: 
https://www4.pucsp.br/webcurriculo/edicoes_anteriores/2008/imprensa.html. Acesso em: 10 out. 2019.

SILVANO, A. M. C. O desenvolvimento de representações gráficas em software educativo para facilitar significativa e colaborativamente a construção do conceito de funções matemáticas. Fortaleza, 2011. Dissertação de Mestrado, Mestrado Profissional de Ensino de Ciências e Matemática, Universidade Federal do Ceará. Disponível em: http://www.repositorio.ufc.br/handle/riufc/2142. Acesso em: 15 nov. 2019.

SILVA, A. C.; D’ÁVILA, C. M. Prática pedagógica lúdica de professores que ensinam Matemática nos anos iniciais do ensino fundamental. REAMEC - Rede Amazônica de Educação em Ciências e Matemática, [S. l.], v. 8, n. 2, p. 232-252, 2020. DOI: 10.26571/reamec.v8i2.10009.

https://periodicoscientificos.ufmt.br/ojs/index.php/reamec/article/view/10009. Acesso em: 20 ago. 2020.

Submetido em: 24 de maio de 2020 .

Aprovado em: 29 de junho de 2020. 